\title{
DEALING WITH TOPOLOGICAL RELATIONS IN UNDERGROUND NETWORKS
}

\author{
M. Lacroix* \\ *METIS Department, Université Pierre et Marie Curie \\ Paris, France \\ 1Spatial \\ Arcueil, France, lacroixmarie@gmx.fr
}

\begin{abstract}
Ten years ago, 25 people died and more than 150 were seriously injured in Ghislenghien (Belgium) because of construction damage to a high pressure gas pipeline. Urban networks are invisible because usually buried between 1 and 1.5 meter underground. They should be identified to prevent such accidents which involve workers and public as well. Rural and urban districts, networks concessionary and contractors; everyone could benefit from their networks becoming safer. To develop software which evaluates the risks in managing both uncertainties and topology is the focus of attention. That's the reason why we firstly propose to determine the topological relationships between networks; secondly we propose to compute the risks taking into account the various uncertainties such as the security radius or the coordinates accuracy, before giving the different required standards for an artificial intelligence tool in order to obtain high security level.
\end{abstract}

Keywords: Topological relations, pipes accidents.

Introduction. The existing networks, the labyrinth of pipelines, big and small, which transport electricity, water, gas from wellhead to home, are big and getting bigger. If pipes are one of the safest methods of transportation for conveying hazardous substances, the loss of containment following a pipeline fracture or accidental release could have disastrous consequences.

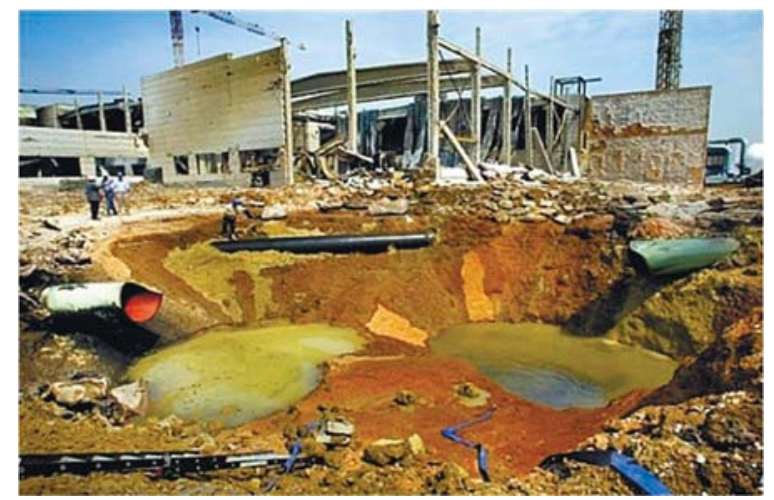

Fig. 6. Picture of the Ghislenghien's explosion (From http://www.lessentiel.lu/news/story/28204100)

In the following table, we can report some of the most important pipes accidents.

Table 1

Examples of pipes accidents

\begin{tabular}{|l|l|l|}
\hline \multicolumn{1}{|c|}{ Town } & \multicolumn{1}{c|}{ Date } & \multicolumn{1}{c|}{ Causes } \\
\hline Ghislenghien (Belgium) & July 2004 & Damaged pipe because of previous work \\
\hline Bondy (France) & November 2007 & Unlisted pipe \\
\hline Niort (France) & November 2007 & A mechanical digger damaged a gas pipe \\
\hline Noisy le sec (France) & December 2007 & Works near a gas pipe \\
\hline Lyon (France) & February 2008 & Works near a gas pipe \\
\hline Plaine de la Crau (France) & August 2009 & Break of a hydrocarbon pipe \\
\hline Sablé sur Sarthe (France) & July 2012 & A mechanical digger damaged a gas pipe \\
\hline East Harlem(USA) & March 2014 & Gas leak \\
\hline
\end{tabular}

That's why it is necessary to acquire and control the 3D information on the different city networks, especially for buried networks in connection with the modernization, maintenance, inspection and elimination of accidents, as well as for access to their location.

Due to the existence of a multitude of underground networks that overlap or intersect, it is important to identify, collect information and study the uncertainties and the topological relations of each network in the vicinity of the other pipes. This paper deals with the characterization and structure of the relations between the networks and their representation. 
The $3 \mathrm{D}$ nature of cities causes data to mount up. On one geographic spot the data may record different networks.

That's the reason why we focus on the representation for geomatic applications. One of the usual representations is the graph. According to the theory, a graph is composed of Vertices and Edges with pair wise relations. Thanks to a succession of Arcs, each of them being defined by two Vertices, a network can be considered as a graph.

Each Arc supports Auxiliary Points (cutting this Arc in Segments). In the same vein, we may add some Furniture (such as manholes for a water network, or street lighting poles for the electric one) between these Auxiliary Points, cutting the Segments in Sections (Fig. 7).

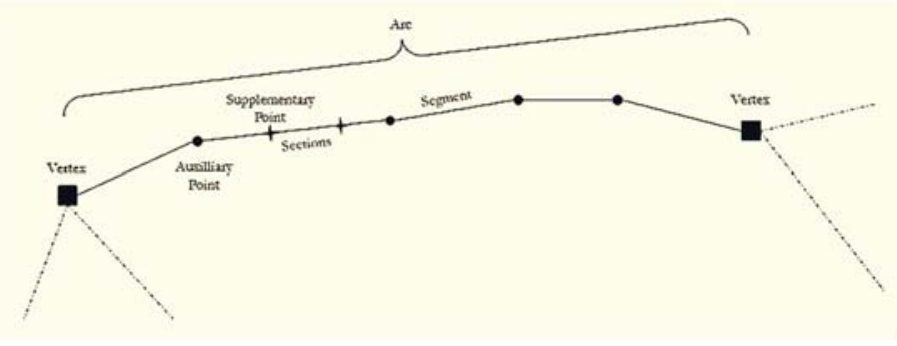

Fig. 7. Graph representation

Another representation of the graph structure is possible with the HBDS ${ }^{[1]}$ one (Fig.8). This method (Hypergraph-Based Data Structure) deduces, directly from the phenomena structure, the data structure. Each element could be represented as a class, an object, an attribute or a link, such as an arc which is an object of the class arc, and so on. In this study, each class depicts an element of the graph (Arc, Section, Vertex, Auxiliary Point which belongs to the arc but isn't a Vertex-,..) and the HBDS structure enables the illustration of the relations between these classes (for instance, Arc 'is composed of' Vertices, Segment 'supports' Supplementary Points, ...).

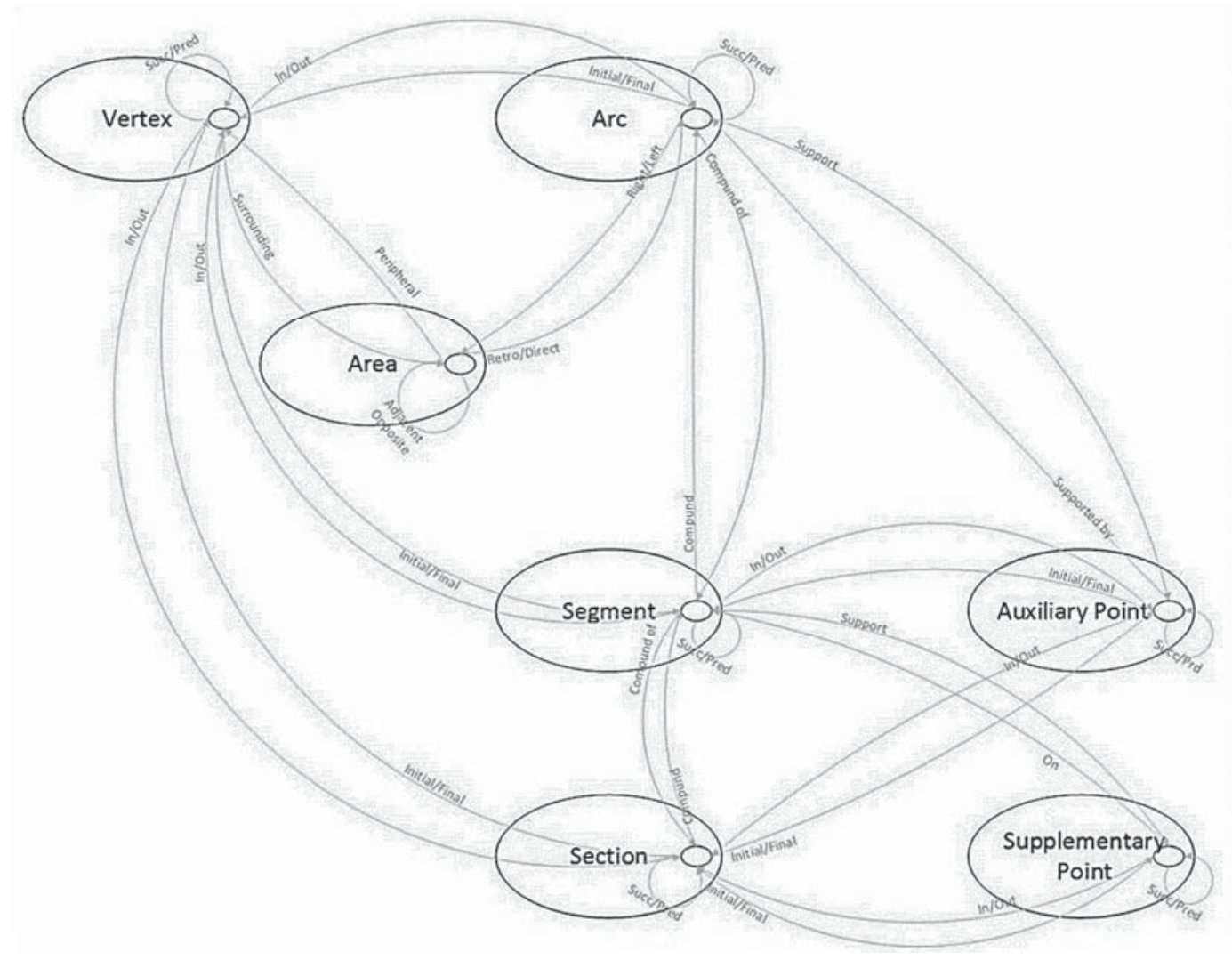

Fig. 8. HBDS Graph organization

Methodology.

Topological relations. Everything has a location, including the furniture of a network. These networks interact with each other, being affected and affecting by whatever they happen to be adjacent to. That's why the study of the topological relations between this pipes is important, and even more if one of them is a very dangerous pipe. 
Illustration of relations between different networks and definition of the topology. Once the graph schematized, it is interesting to work on the HBDS representation of the relationships between different networks (overlays and intersections) (Fig. 9).
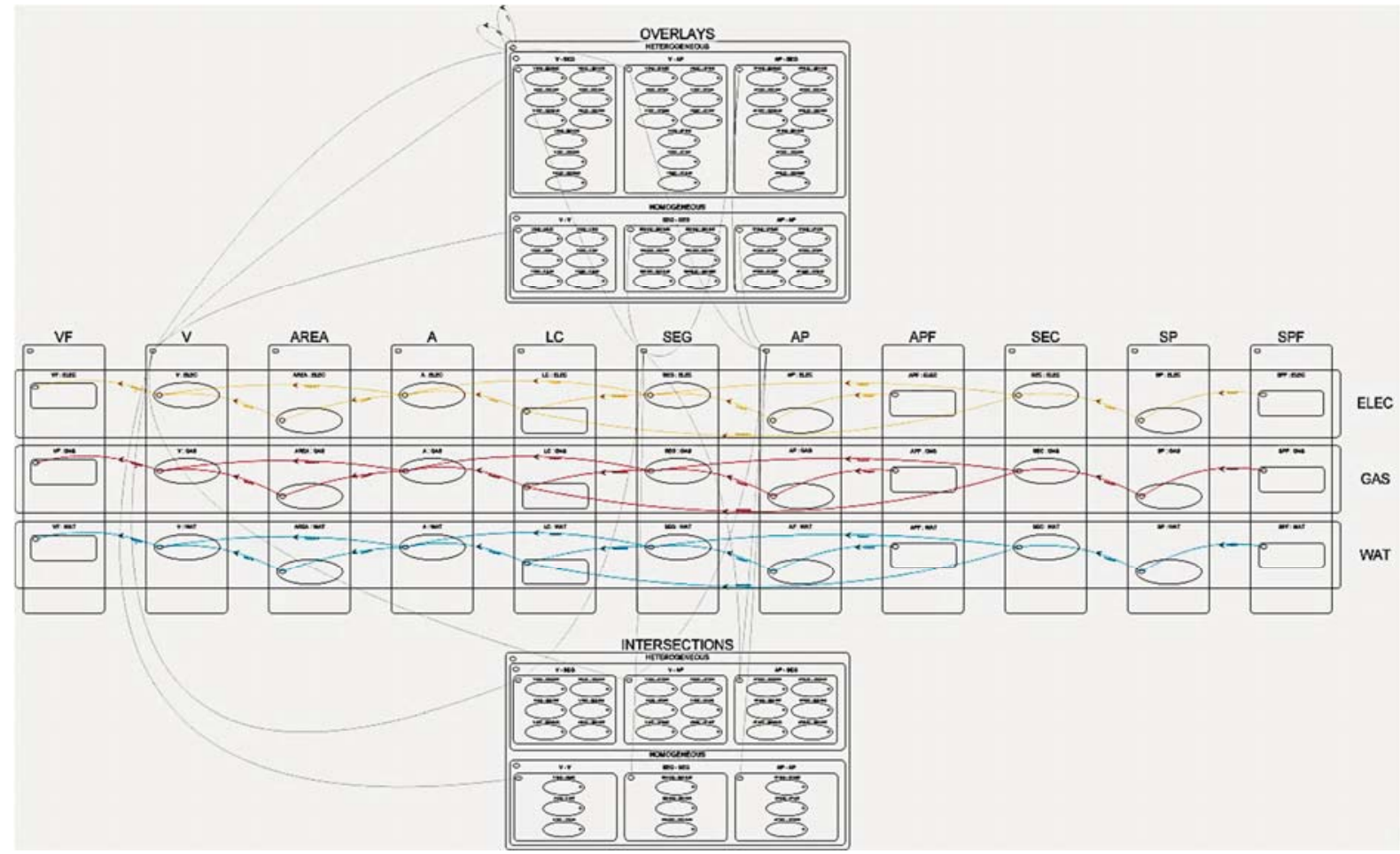

Fig. 9. HBDS of the relationships between three networks (gas, water, electricity)

On this picture three different networks (gas, electricity and water) are taking into account. Firstly, they can intersect each other at the same depth (Fig.10).

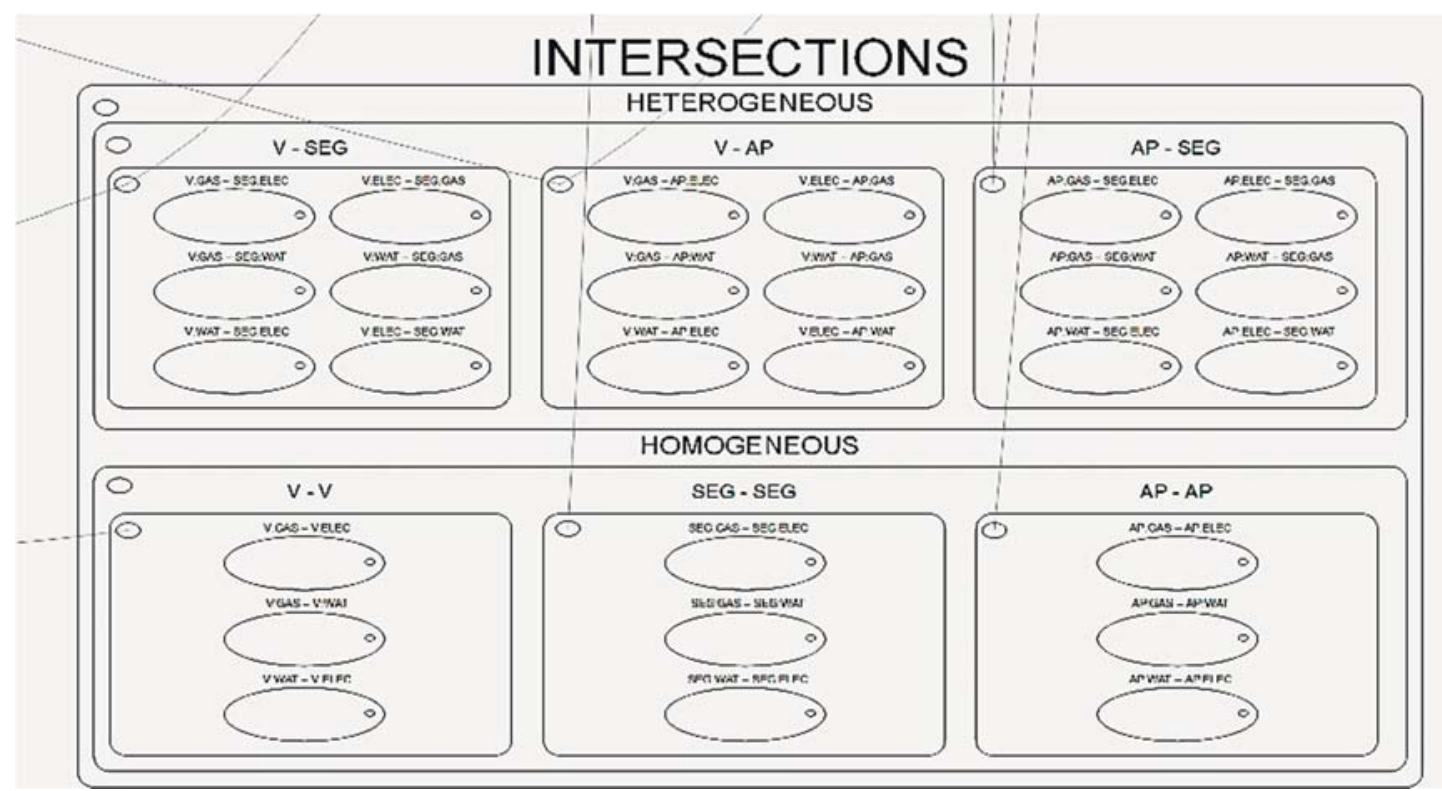

Fig. 10. HBDS of the intersections relations between three networks (gas, water, electricity)

Secondly, they can overlay each other:

- with a linear overlay, described in a following paragraph,

- with a punctual overlay (Fig. 11), almost similar with the intersections. 


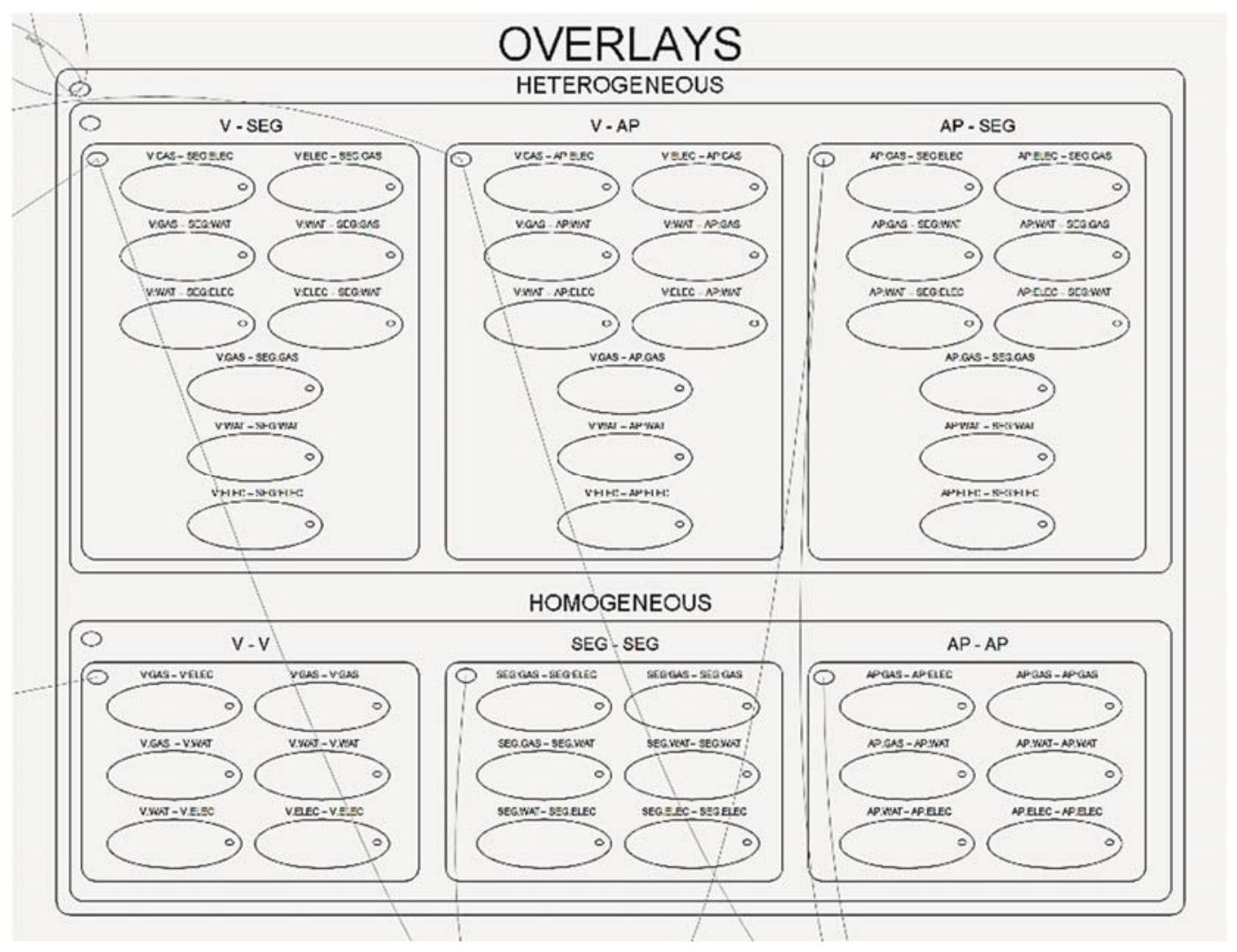

Fig. 11. HBDS of the punctual overlays relations between three networks (gas, water, electricity)

In fact, the topology is a mathematics branch dealing with the relations between different geometric figures (not affected by the distortion of figures relations). This study describes the relations between two networks. There are three main categories ${ }^{[2]}$ :

- homogeneous and heterogeneous intersections,

- overlays,

- altitude comparisons.

Intersections. They imply the existence of a single couple of points (in a plan) from both networks. There are two important categories.

- Heterogeneous intersections

Involve two elements (from each network) of various types.

Different Heterogeneous Intersections

Table 2

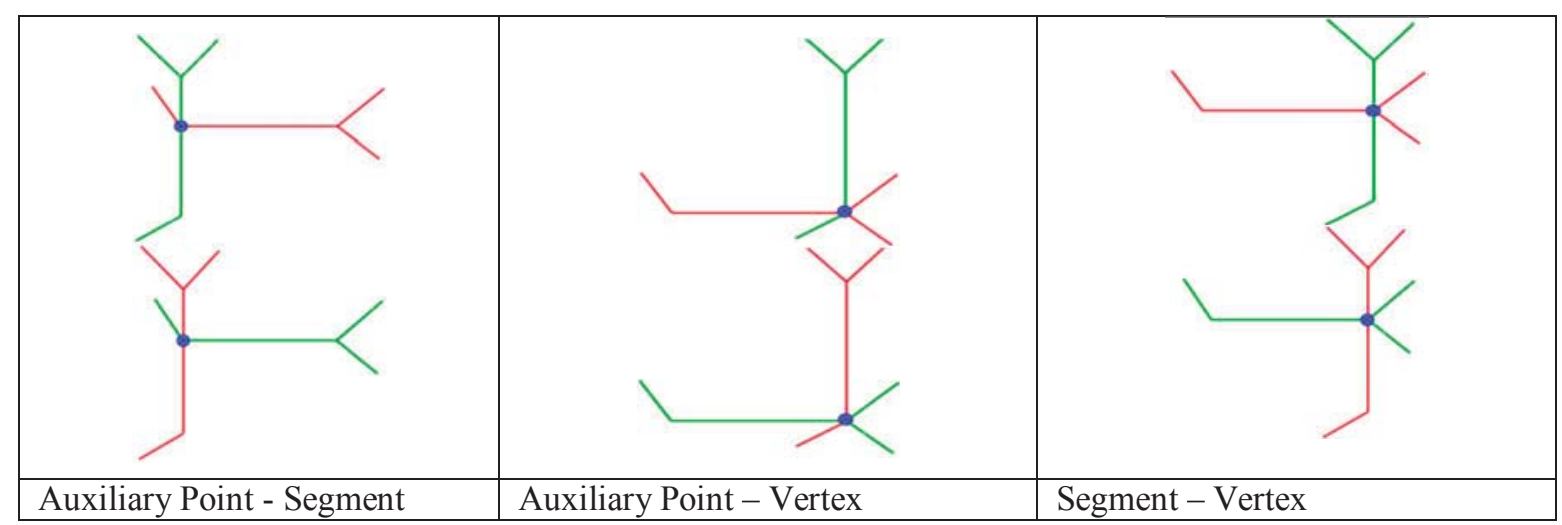

- Homogeneous intersections

Related to a couple involving two members (one from each network) of the same nature. 


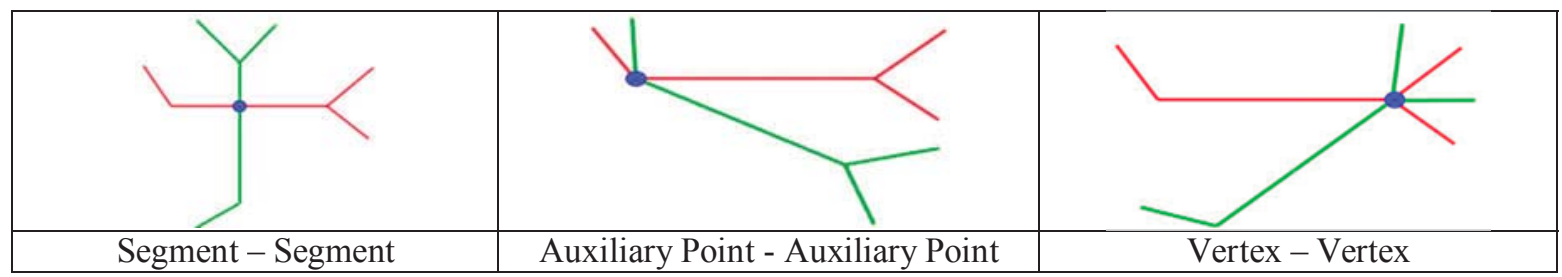

Overlays. The punctual overlays are similar with the intersections (but some overlays may be in only one network). The linear overlays will be described, they assume an infinite number of common pairs (in a plan) from both networks. There are four usual overlays types.

Table4

Different overlays cases

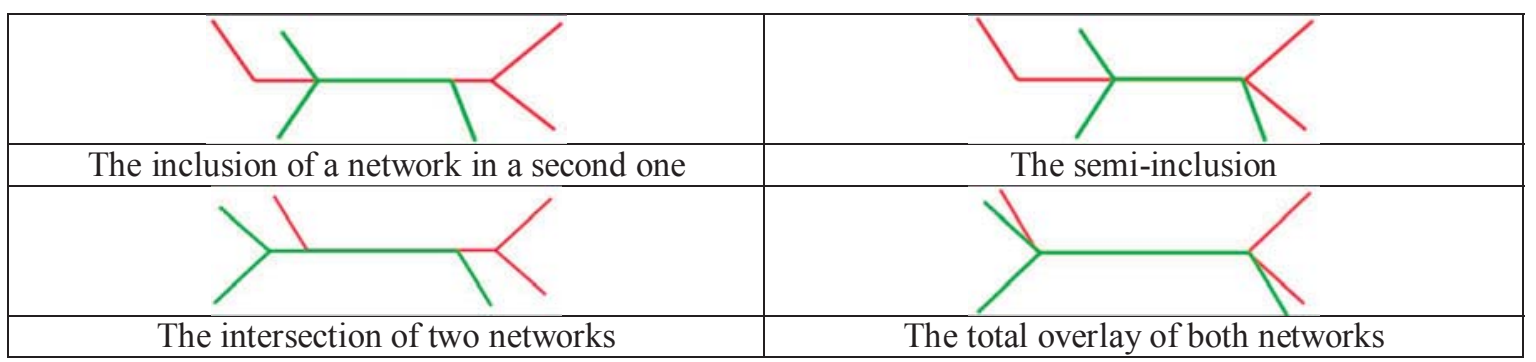

Altitude comparison. Based on two major cases:

- one network is higher than the other one,

- both networks are at the same depth (they can cross or be lined up).

To handle with the topological links, we must determine the metrics between networks.

Managing the uncertainties

Representation of networks uncertainties. The buried pipelines can be depicted, without considering the vagueness (

Fig. 12 (a)) or with blur (

Fig. 12 (b), 7 (c) and 7 (d)).

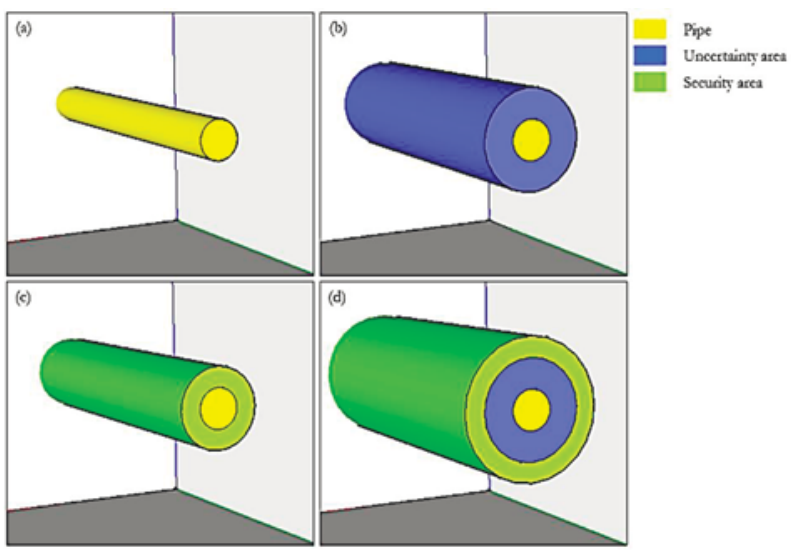

Fig.12. Pipes representation: (a) without blur, (b) with coordinates uncertainty, (c) within the security area, (d) pipe within security area and the uncertainty area

Distance between objects. In order to ease contact calculations, we schematize the pipelines as regular cylinders. This step consists in working the minimal distance between two 3D segments (Euclidian distance) out. According to these distances calculations and to the characterizations of uncertainty, we can define the risks of intersection between different networks.

Taking into account the blur, we'll study the accuracy of the data, and the approximate calculations directly related to significant numbers. 
The Normal Distribution. Depending on the uncertainties and taking into account the security areas of each network, the risk of collision can be determined thanks to the Standard normal distribution over a specified threshold distance (dthreshold) (shown in Fig.13).

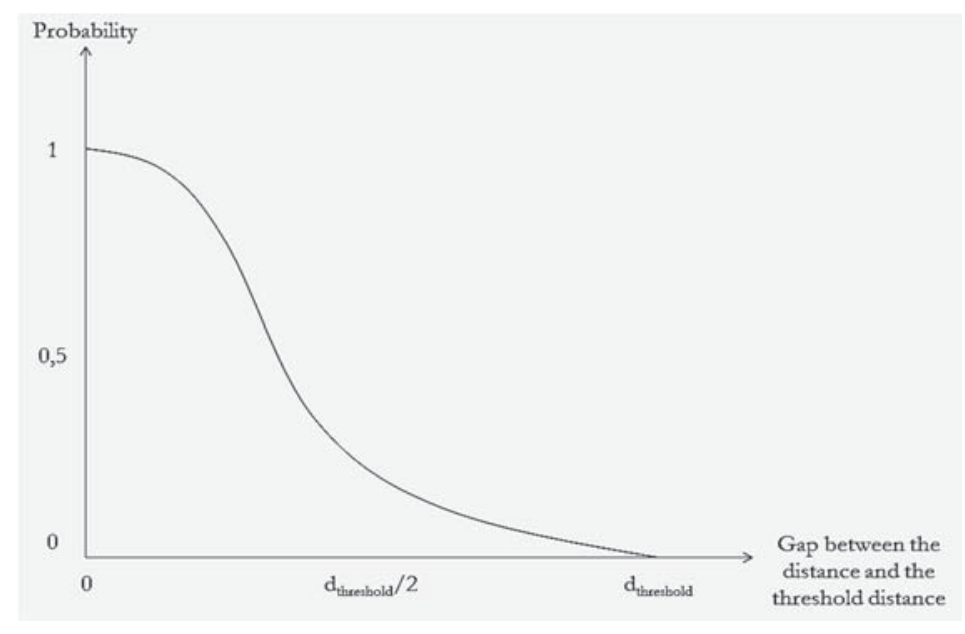

Fig.13. Standard normal distribution representation

The calculation of the threshold distance depends on the elements and their characteristics (like the data precision, the security area). Each characteristic could be optional, that's why some of them are noted between square brackets (Table 5).

\section{Uncertainty calculations}

\begin{tabular}{|c|c|c|}
\hline Category & Threshold distance calculation & $\begin{array}{l}\text { Standard normal } \\
\text { distribution }\end{array}$ \\
\hline Wired - Wired & $\begin{array}{c}\mathrm{d}_{\text {threshold }}=\text { Radius } 1+\text { Radius } 2+\text { Precision1 }+ \text { Precision2 }+ \\
\text { Max }(\text { SecurityRadius1, SecurityRadius } 2)\end{array}$ & $\begin{array}{c}\mu=0 \\
\sigma=\mathrm{d}_{\text {threshold }} / 4\end{array}$ \\
\hline Wired-Element & $\begin{array}{c}\mathrm{d}_{\text {threshold }}=\text { Radius1 + Precision1 [+ Precision2] }+ \\
\operatorname{Max}(\text { SecurityRadius1, [SecurityRadius2] })\end{array}$ & $\begin{aligned} & \mu=0 \\
& \sigma=d_{\text {threshold }} / 4\end{aligned}$ \\
\hline Element-Element & $\begin{array}{c}\mathrm{d}_{\text {threshold }}=[\text { Precision } 1][+ \text { Precision2] }+ \\
\operatorname{Max}([\text { SecurityRadius } 1],[\text { SecurityRadius } 2])\end{array}$ & $\begin{array}{c}\mu=0 \\
\sigma=\mathrm{d}_{\text {threshold }} / 4\end{array}$ \\
\hline
\end{tabular}

Artificial intelligence tool. The development of an Artificial Intelligence tool contributes to the challenge of provide the users and consumers a unique tool set able to (according to the input data):

- determine the fluids classes,

- define the kinds of pipes,

- inform about the required standards associated with the networks characteristics,

- assess level accuracy and so define the risks of damage.

These various forms of data all contribute to the challenge of running and achieving the programs, according to the requests of the users.

The next paragraphs are dealing with the examples of the French regulation called "Arrêté Multifluide" (concerning dangerous networks) and "Réforme DT/DICT" (referring to the security area around a network and, more especially, when its coordinates have an important uncertainty). These examples are given in the three next tables and represent the basis of the rules-data-set of the Expert System developed in this Software.

Fluids classes. Government authorities published required standards for fluids classification.

Table 6

Table of fluids classes

\begin{tabular}{|l|l|}
\hline A & Not flammable and not toxic fluids, in liquid phase, in the ambient temperature and the atmospheric pressure \\
\hline B & Flammable or toxic fluids, in liquid phase, in the ambient temperature and the atmospheric pressure \\
C & $\begin{array}{l}\text { Not flammable and not toxic fluids, in gas phase, in the ambient temperature and the atmospheric pressure, } \\
\text { including the oxygen }\end{array}$ \\
\hline $\mathrm{D}$ & Fuel gases \\
\hline $\mathrm{E}$ & $\begin{array}{l}\text { Not belonging to the D class, flammable or toxic, in gas phase, in the ambient temperature and the } \\
\text { atmospheric pressure, even if carried as gas form or liquefied, and carbon dioxide too. }\end{array}$ \\
\hline
\end{tabular}


These various forms of potential risks data all contribute to the known quality of data for security. That's why authorities published a pipe classification, as well.

Pipes categories. There are three kinds of pipes, according to several criteria:

- the nature of the carried product,

- the vicinity,

- the surrounding population (and the possibility of lethal effects).

Table of pipes categories

\begin{tabular}{|c|c|c|}
\hline \multirow{6}{*}{ A } & & No E class product allowed \\
\hline & $\begin{array}{l}\text { Carried } \\
\text { product }\end{array}$ & $\begin{array}{c}\text { When carried product is D-Class: } \\
\text { Outside diameter (without cove) }>=500 \mathrm{~mm} \\
\text { Not in slopes }>20 \% \\
\text { Not in wet zone } \\
\text { Distance greater than or equal to the distance of the first lethal effects in case of a disaster } \\
\text { scenario when the occupation density is greater than } 8 \text { people by hectare }\end{array}$ \\
\hline & Domain & In the private or the municipal public domain, except river or granted public domain. \\
\hline & Place & $\begin{array}{l}\text { Not located in a urban unit (INSEE - National Institute for Statistics and Economic Studies), } \\
\text { neither in a U, NA or NB area of a municipality covered by a municipal map, nor in the urban } \\
\text { parts of a municipality which is not covered by town map document }\end{array}$ \\
\hline & Housing & Neither human accommodation nor human activity zone at a distance lower than $10 \mathrm{~m}$ \\
\hline & $\begin{array}{l}\text { Significant } \\
\text { lethal effects }\end{array}$ & $\begin{array}{c}\text { In a zone centered on the pipe, with radius equal to the distance of the significant lethal effects } \\
\text { in case of complete break of the pipe, the housing number corresponds to an occupation } \\
\text { density lower than } 8 \text { people by hectare and to a total occupation density (including housing } \\
\text { and human activity) lower than } 30 \text { people }\end{array}$ \\
\hline \multirow[b]{2}{*}{ B } & & Neither in A nor C category \\
\hline & & $\begin{array}{l}\text { A carrying E class product pipe cannot be classified in B category excepted when the pipe was } \\
\text { already in order before the } 04 / 08 / 2006 \text { application }\end{array}$ \\
\hline \multirow[t]{3}{*}{$\mathrm{C}$} & \multirow[t]{3}{*}{$\begin{array}{l}\text { Carried } \\
\text { product }\end{array}$} & $\begin{array}{c}\text { Fuel gases transportation or area centered on the pipe with a radius equal to the distance of the } \\
\text { significant lethal effects corresponding to the disaster scenario, are housing or places: } \\
\text { in a population density greater than } 80 \text { people by hectare } \\
\text { or in a total occupation of more than } 300 \text { people }\end{array}$ \\
\hline & & E class Product transportation \\
\hline & & The carrying E class product pipe was already in order before the 04/08/2006 application \\
\hline
\end{tabular}

Networks implantation.Creating a rules-based data set means a major challenge to meet the security required standard. The last significant steps concern the networks implantation and the coordinate accuracy determination.

The various forms of rules for the networks implantations depend on the 'internal' characteristics concerning the pipes (transport or distribution, diameter, material,...), the local topography (trenches, slopes, minimal depths,...) and the devices of reassurances (security area, warning materials,...).

Accuracy classes and DT-DICT regulation

Imply two subsets:

- the definition of the precision classes,

- the risks of damage according to the works.

Table 8

Table of accuracy classes

\begin{tabular}{|l|l|}
\hline & $\begin{array}{l}\text { The maximal location uncertainty given by the concessionary is lower than or equal to: } \\
40 \mathrm{~cm} \text { if the urban work is inelastic, }\end{array}$ \\
A & $\begin{array}{l}50 \mathrm{~cm} \text { if the urban work is flexible } \\
80 \mathrm{~cm} \text { if the buried work concern trains or if they have been built before } 01 / 01 / 2011\end{array}$ \\
\hline B & Neither A nor C \\
\hline C & The maximal location uncertainty given by the concessionary is greater than $1,5 \mathrm{~m}$ or in case of unknown data. \\
\hline
\end{tabular}

Results. Applications of the management of the uncertainties. Users planning an excavation in the vicinity of a pipeline need to know the relations between networks and the risks of contact between them, taking into account the different types of blur (especially the data uncertainties and the security radius).

The next sections illustrate some applications and the risks visualization, depending on the scenarios. 
These examples are based on a factice data set (Fig. 14) composed of a Digital Elevating Model (DEM), a trench and five pipes with different characteristics (Ошибка! Источник ссылки не найден.).

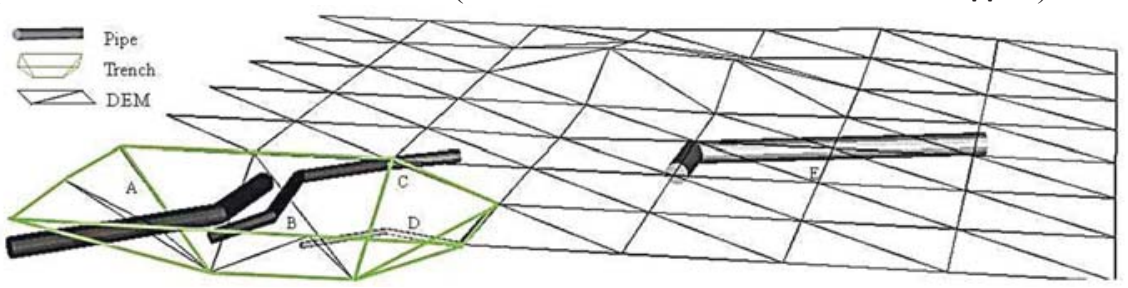

Fig. 14. Factice data set

Table 9

Pipes characteristics

\begin{tabular}{|c|c|c|c|c|c|c|c|}
\hline Pipe & Radius (m) & $\begin{array}{c}\text { Security } \\
\text { distance } \\
(\mathrm{m})\end{array}$ & $\begin{array}{c}\text { Uncertainty } \\
\text { radius }(\mathrm{m})\end{array}$ & $\begin{array}{c}\text { Point 1 co- } \\
\text { ordinates }\end{array}$ & $\begin{array}{c}\text { Point 2 co- } \\
\text { ordinates }\end{array}$ & $\begin{array}{c}\text { Point 3 co- } \\
\text { ordinates }\end{array}$ & $\begin{array}{c}\text { Point 4 } \\
\text { coordi- } \\
\text { nates }\end{array}$ \\
\hline A & 1.5 & 0.9 & 0.4 & $0,0,6$ & $22,18,7$ & $24,32,8$ & \\
\hline B & 1 & 1 & 0,4 & $20,20,3$ & $27,25,5$ & $25,45,5.5$ & \\
\hline C & 1 & 1 & 0.4 & $25,45,5.5$ & $35,55,5.5$ & $45,60,6$ & \\
\hline D & 0.5 & 1 & 0.4 & $25,45,-5$ & $35,55,-5$ & $45,60,-8$ & $45,80,-8$ \\
\hline E & 1.8 & 1.5 & 0.4 & $75,75,6$ & $76,85,7$ & $120,100,7$ & \\
\hline
\end{tabular}

This software target is to answer to different scenarios:

- the contractor can verify when his trench (modification of the DEM) disturbs or not the networks. If a pipe is impacted by the trench, the software colors it in red.

- districts or concessionary can verify that the networks (implanted or under consideration) are not deeply buried enough. The software will color such pipes in red.

- the utility and construction contractors, and districts as well, can verify that their networks (still implanted or under consideration) don't disturb existing networks in the vicinity. The developing software will color the impacted networks in blue. colors them in purple.

- when networks are impacted by other networks and moreover they are not deeply buried, the software

This figure (Fig. 15) represents the different scenarios (the pipe $\mathrm{C}$ is affected by another pipe, the pipe $\mathrm{E}$ is impacted by the ground, the pipes A and B are both affected by the ground and surroundings networks, and the pipe D isn't impacted).

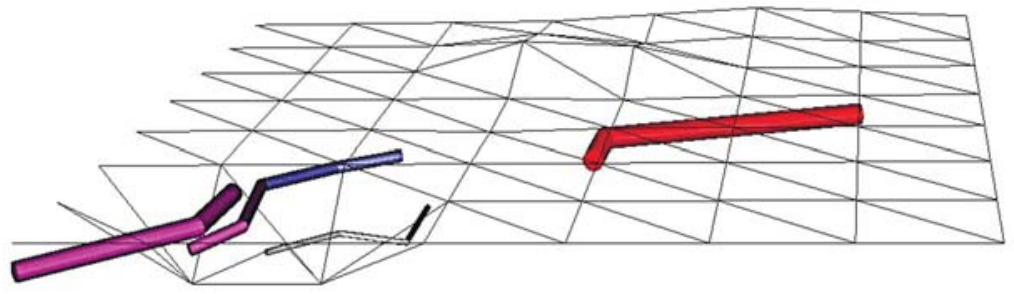

Fig. 15. The risks evaluation representation

To evaluate the risks, the general reasoning is:

Algorithm 1: The risks evaluation algorithm

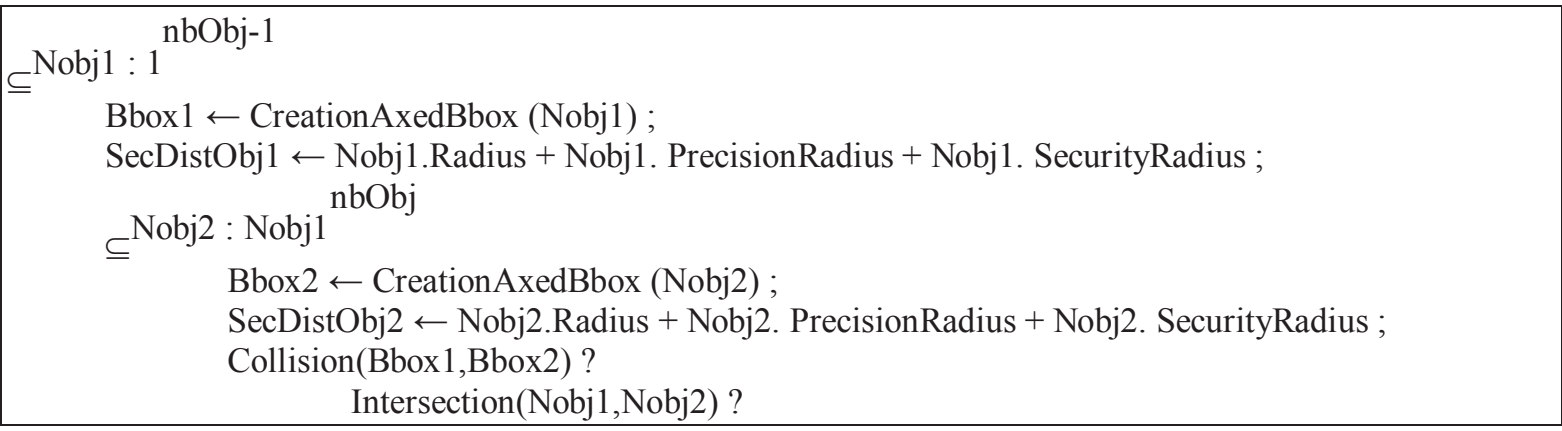




\begin{tabular}{|c|c|c|}
\hline & & $\mathrm{U} 1 \leftarrow\{[$ SecDistObj1-(dthreshold-distance) $]-\mu\} / \sigma ;$ \\
\hline$\in^{\text {Nobj1 }} \in^{\text {Nobj2 }}$ & $\left.\right|^{\prime}$ & $\begin{array}{l}\mathrm{U} 2 \leftarrow\{[\text { SecDistObj2-( dthreshold -distance })]-\mu\} / \sigma \\
\text { TotalProbability } \leftarrow \text { Computation(Prob(U1), Prob(U2)) }\end{array}$ \\
\hline
\end{tabular}

Topology algorithm. In the wired-wired case, we must compare, trunk by trunk, the pipes (by pair) to define their topological relations in the XY plan.

Algorithm 2: The topological algorithm

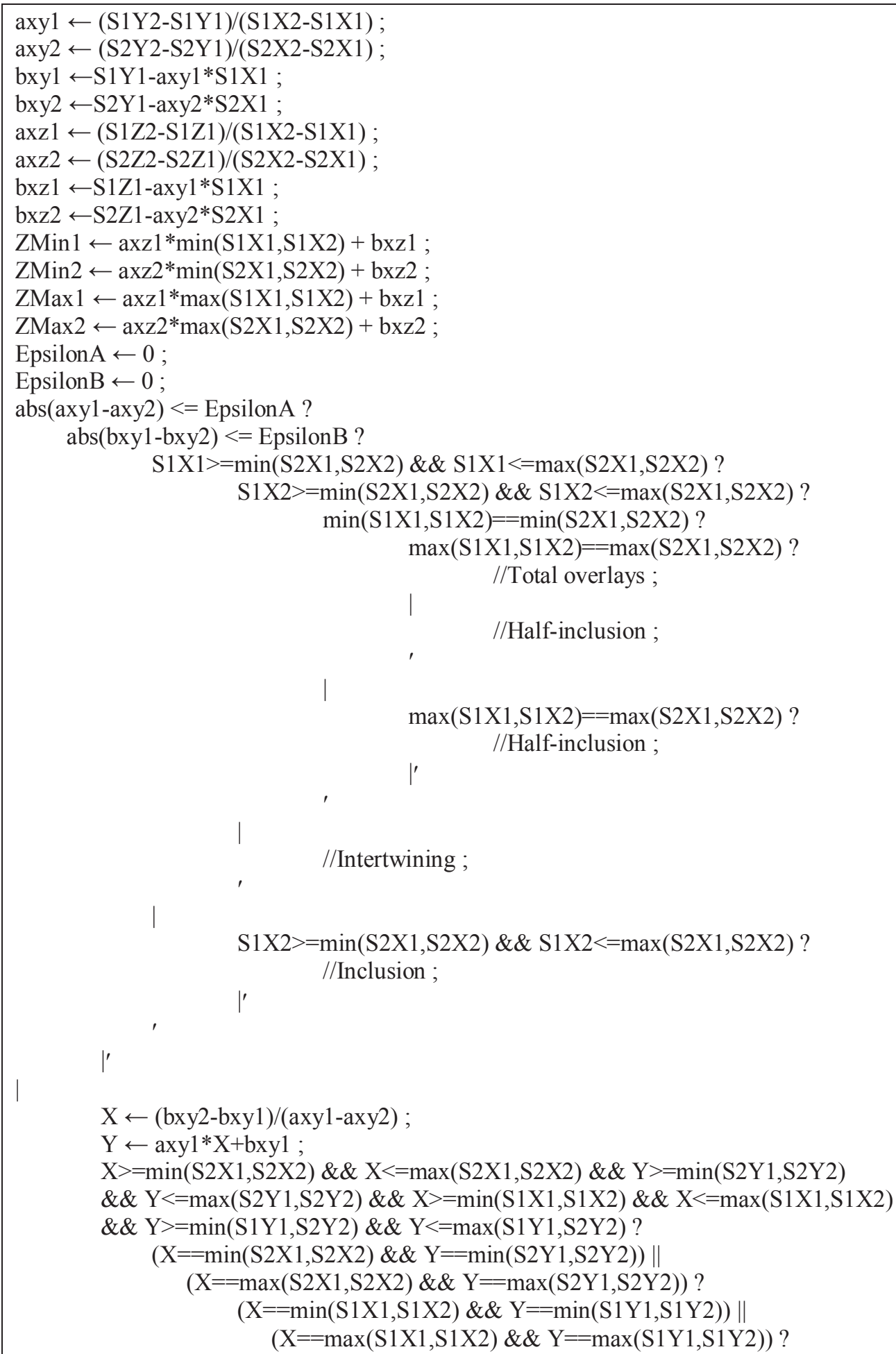




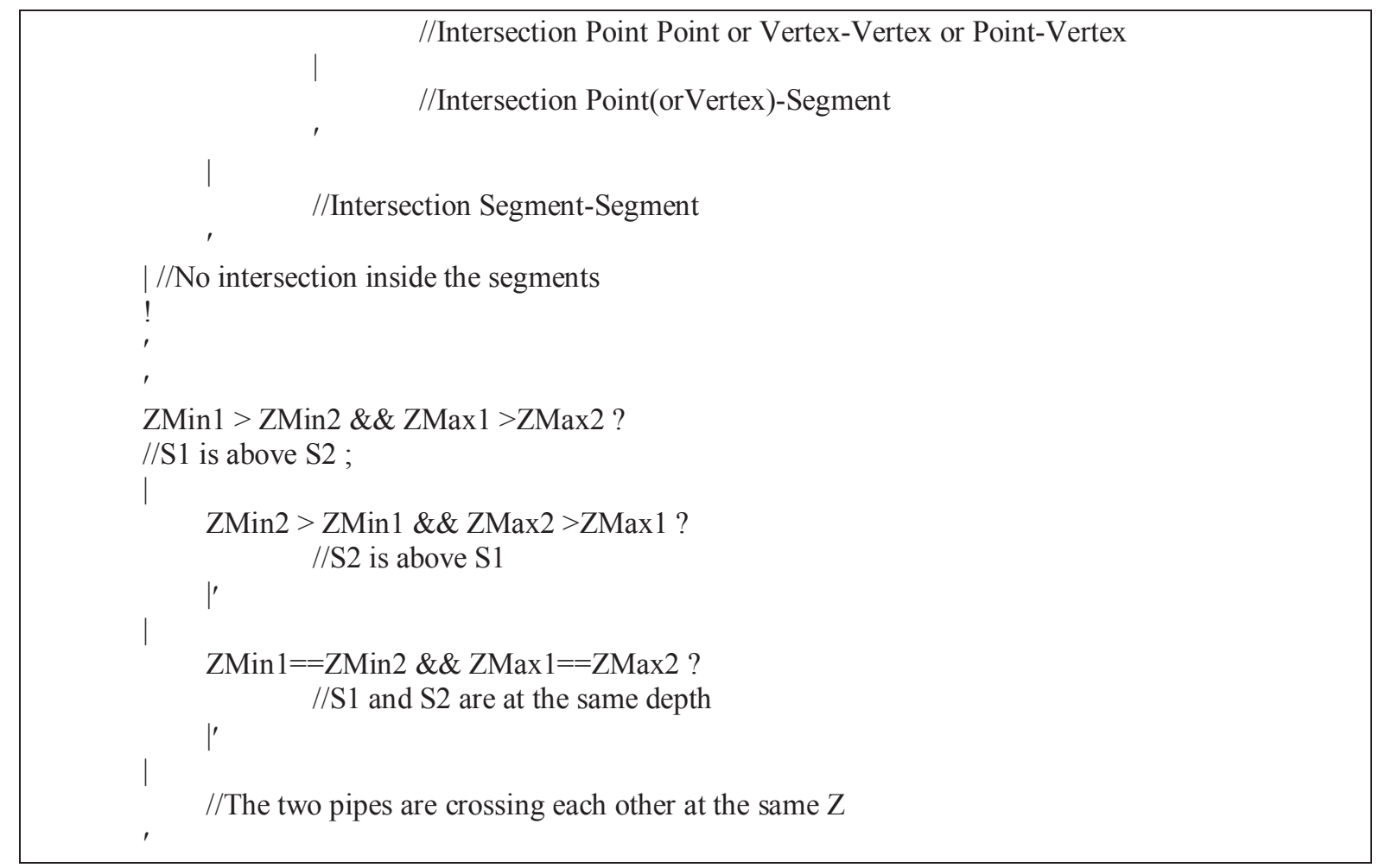

The Expert System reasoning. In this paragraph, some examples of formulated rules will be presented. They are dealing with the different regulations examples presented in some previous sections. And, Or...).

In an Expert System, a rule is an expression composed by facts connected by some logical operators (like

These rules could concern:

- materials for a type of pipe

If the pipe is carrying gas

SO the warning materials must be yellow

- building rules

If the pipe is carrying electricity

SO the minimal depth is $0,20 \mathrm{~m}$

- security rules to take into account if two networks are impacting each other

If a plumb pipe is carrying gas

AND a pipe is carrying warm water is in the surroundings

AND the two pipes are parallel

SO the distance between the pipes must be greater than or equal to $3 \mathrm{~m}$

For example, we have this algorithm:

Algorithm 3: The Artificial Tool algorithm

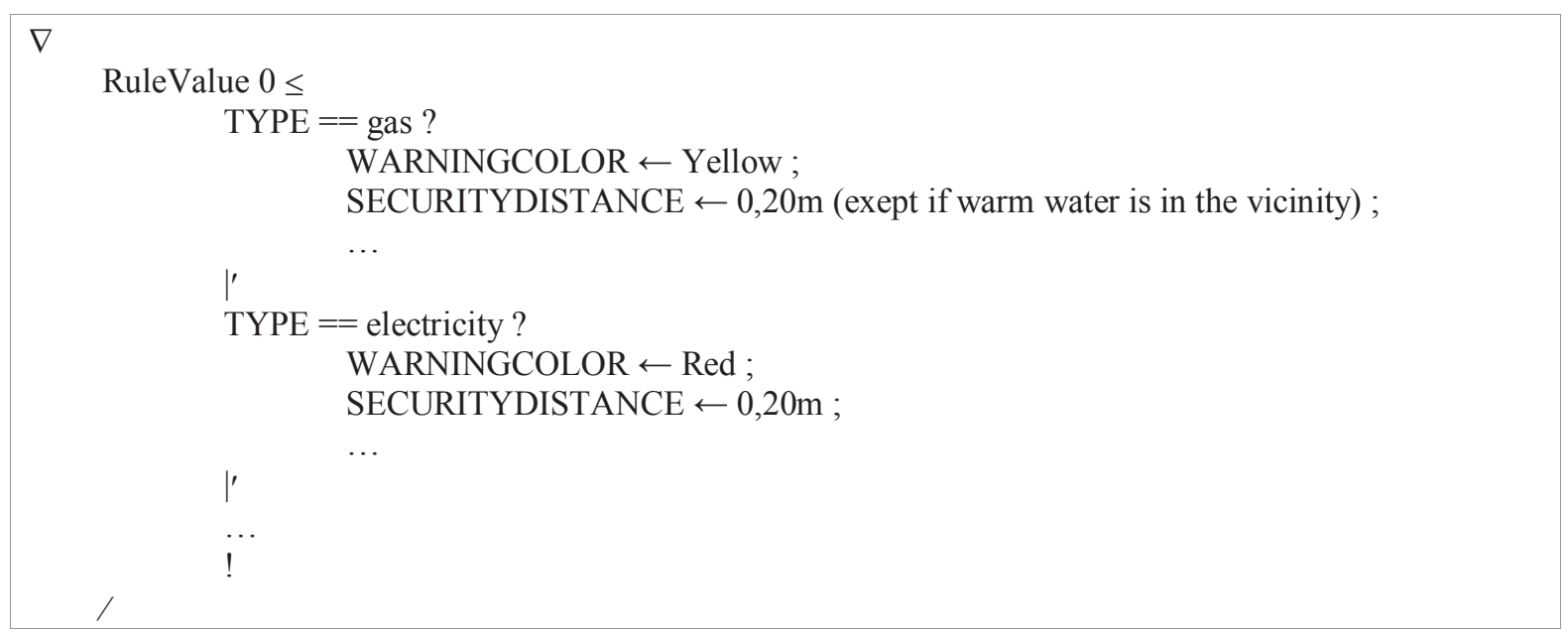




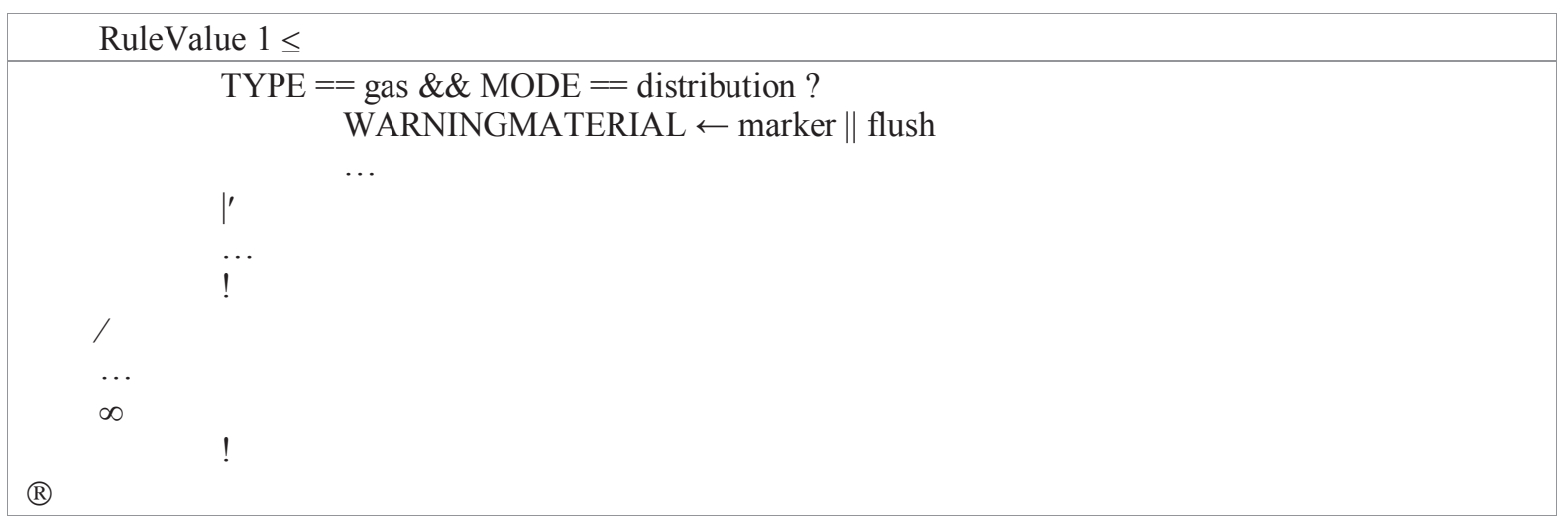

Conclusion. Disasters like the one that happened in East Harlem have been attributed to an aging gas network whose pipelines may corrode and rupture. Leaks can also happen as a result of excavation orclimate event, as it was the case in the loss of New Orlean's gas network after Hurricane Katrina in 2005. Tragic occurrences, such as Ghislenghien's, push to make system safer. Moreover the 3D nature of cities causes data to mount up. That's why creating a rules-based data set for users and consumers, represents a significant step for high level security

Knowledge bases must replace classical data bases. Working on the networks and their relationships, taking into account the blur, are a recent and appropriate research. These software applications will give the utility and construction contractors help and focus on prevention of hazardous events.

\section{REFERENCES}

1. Bouillé F., 1977, "Un Modèle Universel de Banque de Données Simultanément Portable, Répartie”.

2. Bouillé F., 2012, "Chapitre 10.6 - Relations entre réseaux - Superposition, intersection, emboîtement", http://fad.ensg.eu/moodle/course/category.php?id=12.

3. 2nd Int.Conf. on Design and Decision Support Systems in Architecture and Urban Planning, Vaals : 'Mastering urban network intersection and superimposition, in an object-oriented knowledge system integrating rules, neurons and processes', 1994, Aug. 15-19, 15 p.

4. GIS Int.Conf. 'Europe in Tansition', Brno: 'Object-oriented methodology of structuring multiscale embedded networks', 1994, Aug. 28-31, Proceed., chap.I, pp. 2-18.

5. GIS Int.Conf. 'Europe in transition', Brno: 'Towards 2000: the actual main trends in future GIS', 1994, Aug. 28-31, Proceed., chap.K, pp. 13-27. 